\title{
The Varying Impact of Geographic Distance as a Predictor of Dissatisfaction Over Facility Access
}

\author{
Alexis Comber • Chris Brunsdon • Martin Phillips
}

Received: 17 February 2011 / Accepted: 21 December 2011 /

Published online: 27 January 2012

(C) Springer Science+Business Media B.V. 2012

\begin{abstract}
This research uses a Geographically Weighted Regression (GWR) analysis to compare perceptions of public service accessibility as captured by an attitudes survey against measures of geographical distance to those services. The 2008 Place Survey in Leicestershire, UK, captured data on respondent dissatisfaction about their access to different services and facilities. In this analysis, survey responses about access to Post Offices and libraries were summarised over census Output Areas. Road distances to the nearest facility were calculated for each Output Area. GWR was used to model the spatial variations in the relationship between facility distance and access dissatisfaction and how these relationships vary within and between different socioeconomic groups (in this case OAC groups). The results show that for Post Offices, the effect of geographic distance as a predictor of access dissatisfaction is stronger than for libraries, that its effect varies spatially and that there is considerable variation within and between different socio-economic groups. For Libraries, geographic distance is a weaker predictor of dissatisfaction over access, there is little local variation in the effect of geographic distance as a predictor of library access dissatisfaction and that there is little variation within and between different socio-economic groups. These results indicate that as well as geography, other dimensions related to facility access need to be considered and that these will vary from facility to facility and from group to group.
\end{abstract}

Keywords Place survey $\cdot$ Access/Accessibility $\cdot$ Post office $\cdot$ Library

\footnotetext{
A. Comber $(\bowtie) \cdot$ M. Phillips

Department of Geography, University of Leicester, Leicester, LE1 7RH, UK e-mail: ajc36@le.ac.uk

C. Brunsdon

Department of Geography, University of Liverpool, Liverpool, L69 3BX, UK
} 


\section{Introduction}

Issues of service provision and access have long been the subjects of academic and policy attention especially in rural areas (e.g. Bracey 1953; Moseley 1978, 1979; Lowe et al. 1986; Bell and Cloke 1990, 1991; Higgs and White 1997; White et al. 1997; Farrington and Farrington 2005; Comber et al. 2009; Langford and Higgs 2010). Evaluations of service or facility access can be divided into two groups: one considering the spatial dimensions of geographic access (distances, travel times, catchments, etc.), the other analysing the underlying socio-economic aspects of access that relate to the ability of individuals to access facilities such as cost, perceptions of service, quality, previous experiences and the behavioural aspects of access. This paper develops an analysis that links these different tranches of accessibility research by combining analyses of public perceptions of public service accessibility from an attitudes survey with analyses of geographic road distance to those services. It uses Geographically Weighted Regression (GWR) to analyse the relationships between perceptions of accessibility to 2 facilities, libraries and Post Offices with geographic distance to the nearest facility. These were chosen as public services to analyse because they are commonly included in narratives about reductions in service provision and planned closures and because the perform different functions: Post Offices are seen as performing key social and economic functions, especially in rural areas, and libraries have long been held as important for educational and cultural development, and more recently as information hubs.

Analysing public service accessibility is of particular current concern in the UK because of the emerging 'Big Society' agenda of the government which proposes fundamental structural reform in the relations between state and society, encompassing devolution of power from central government, local autonomy, restructuring of welfare and health provisions and reduction of state expenditure (Cabinet Office 2010). Under these agendas, reductions in the state provision of services are to be replaced by individuals and communities taking on responsibilities for service provision. There is concern that such reductions in provision and formal (state) infrastructure may accentuate processes of socio-spatial marginalisation and exclusion: some people and places with specific combinations of high levels of economic, social and cultural capital may experience further improvements in relative service accessibility, while other people and places with limited levels of such capitals are more vulnerable and may see sustained, and self reinforcing, levels of service reduction. Using GWR to analyse the spatial variations in the relationship between perceptions and geography for different geodemographic groups provides a spatially nuanced analysis of how different variables interact across the study area and how interaction varies spatially within and between different socioeconomic groups.

One of the fundamental tenets of geographical data analyses is to evaluate the potential existence of spatial variability in relationships between attributes. GWR is a spatially explicit regression technique (Fotheringham et al. 2002; Brunsdon et al. 1996) and allows one to consider (and to test for) the possibility that relationships can vary over geographical space, by allowing regression coefficients to vary with location. In this way GWR is a technique that deals with spatial non-stationarity in 
multivariate regression (Fotheringham et al. 1997) by estimating regression coefficients locally using spatially dependent weights with the weight of data points being determined by their distance from each of a given number of estimation locations. GWR is becoming a more commonly used technique in computational geography and has been used to investigate non-stationarity in a number of domains including health (Nakaya et al. 2005), education (Fotheringham et al. 2001), regional economies (Huang and Leung 2002) and as a method of spatial disaggregation (Li et al. 2009). Hitherto, GWR has not been used to analyse attitude survey data nor to compare such responses with quantitative geographical measurements. Only in a few instances have qualitative and quantitative measures of access have been analysed and the spatial variations in the relationships explored. Maroko et al. (2009) used GWR to explore the spatial relationships between the variables associated with models of park acreage and density of physical activity sites.

There has been little research that has examined how the different dimensions associated with access interact, how they vary spatially, how they vary across different socio-economic groups and for different types of facility. This paper addresses such gaps by using GWR to consider perceptions of access with geographic measures of access for different geodemographic groups. In so doing, it emphasises the need for multi-dimensional analyses of access, the need to consider local, spatially explicit statistical models, as opposed to global ones, and the need to examine how these relationships vary within and between different socio-economic groups. The suggested method is one that could be used to indicate areas, and specific socioeconomic groups in specific areas, that are potentially vulnerable to reductions in public service provision.

\section{Background}

Much previous research has examined spatial or geographic access to different services and facilities, often with the objective of informing decision making in spatial planning and policy. Typically in such studies, access to a particular service (e.g. health, greenspace, post offices, libraries, food) is quantified for different social groups (e.g. urban/rural, religious, ethnic, socio-economic status). Demographic data is summarised over spatial units such as post code districts, census areas, floating catchment areas, residential addresses or service/facility catchments and then GIS-based measures of distance (Euclidian or network) are calculated. Recent examples include studies of access to Post Offices (Langford and Higgs 2010; Comber et al. 2009), food outlets (Forsyth et al. 2010; McEntee and Agyeman 2010) and health facilities (Sasaki et al. 2011). In some cases, such analyses have been extended to compare current and future populations (Sasaki et al. 2010) to support long term facility planning and to answer the location-allocation problem associated with identifying the optimal location of facilities (e.g. Comber et al. 2009; Comber et al. 2011).

This tranche of accessibility research has been developed to identify gaps and inequalities, to evaluate service provision and policy plans and to highlight geographic regions with low service coverage. The work has frequently referenced concepts such as social justice, social inclusion, environmental justice, public participation and 
public engagement, while the location-allocation extension work considers how best to spread resources to minimise those gaps and the number of people (service users) without access. In general, these various analyses have adopted rather narrow notions of 'access', centred on the quantitative spatial analyses of service provision and service accessibility based on physical distance measures, albeit with growing sophistication in analysis. White et al. (1997) and Langford and Higgs (2010), for example, have applied GIS to analyse changes in post office provision and associated subsequent impacts on accessibility, whilst Comber et al. (2009) developed a model to optimise closures patterns against stated accessibility objectives and many other similar examples of GIS-based analyses of accessibility can be found in the literature. However, omissions from such analyses include the behavioural aspects of service accessibility. Whilst people might have a service within some normatively accessible distance, there has been little analysis of whether people actually access this service, either failing to make use of any such service or making use of some more distantly located services. The latter situation might well reflect, public perceptions of service accessibility linked to a range of highly qualitative influences, including perceived service quality, opening hours and previous experiences. The failure to make use of any such service might well be viewed as indicative of social exclusion, whilst using more distantly located services might be seen to reflect the exercise of choice. Use of more distant service outlets has actually been shown to be quite commonplace in studies of rural retailing, where, for example, the declining use of village shops, post offices and schools have all been ascribed to people travelling beyond the village to access other outlets, perhaps due to lower commodity costs, greater stock range or quality, or proximity to place of work or daily travel routes for work or schooling (Prentice 1991; Pinkerton et al. 1995; Findlay et al. 2001; Bowden and Moseley 2006; Powe and Hart 2009).

Adopting a specifically spatial definition of 'access' allows relatively straightforward spatial analysis using tools such as a GIS. However 'access', as described above, is more complex than simple distance measures and encompasses much a wider set of concepts. Early work by Aday and Andersen (1974) identified two general themes in different concepts of health care access relating to population characteristics such as income, insurance coverage and attitudes the specific service and what they term the "delivery system" relating to the distribution and organization of facilities. This distinction persists in much health planning research. More recent work indicates the multidimensionality of the concepts of access and accessibility. Farrington and Farrington $(2005$, p.2) observed that accessibility can be viewed as "the ability of people to reach and engage in opportunities and activities" and generally involves overcoming social dimensions of access and separation, as well as spatial constraints. For example, work by Gray et al. (2006) noted that access to services in rural areas depended on a range of different combinations of journey-making opportunities and constraints which were linked to the specific characteristics of particular localities, the institutions and people that reside there. This highlights the significance of the social dimensions associated with accessibility, with both the availability of services and transportation to access them being conditioned by, as well as conditioning, the social resources available to particular people, households, communities and organizations. Gray et al. (2006) draws upon the arguments of Urry (2002) concerning the significance of social capital in maintaining systems of mobility and suggests that studies of 
accessibility need to consider how these are often underpinned by networks of social of capital. These issues are particularly acute in rural and remote areas or for groups of people where private transport is not readily available. Gray et al. (2006) identify 'lift-giving' as a relatively common practice in some areas and other forms of social capital may also be significant such as participation in community activity (Mahar 1991; Atkin 2003; Tyler 2006; Phillips 2010).

The proposed structural reforms reducing the relationship between the state and society will replace national 'public service agreements' that describe normative standards of service accessibility that people should reasonably expect to receive (Farrington and Farrington 2005) with a localist approach whereby individuals and communities will have "new rights to bid to run services and to save facilities at risk of closure", including the "right to bid to take over local state-run services" (DCLG 2010). Such changes are packaged by the Government as a mechanism for improving public services by making them more tailored to local needs, reducing regulatory overheads and encouraging innovation. However, there is clear potential that these changes may well lead to increased spatial and social inequalities in accessibility to services as well as service fragmentation, differentiation and potential decline. It has, for example, been argued that over $70 \%$ of local authorities will be reducing subsidies to rural bus services (Campaign for Better Transport 2011a), which it is claimed will lead to a closure of many bus routes and severely impact on the lives of some of the most disadvantaged groups in rural society (Campaign for Better Transport 2011b)

In summary, much geographic research has considered access based on distance measures. In the social sciences, notions of access have been related to abilities to engage with a service. The impacts of reductions in public services and thus service accessibility that are being proposed will depend on the interaction between different factors. The ability of communities to develop their own strategies to access services and to overcome the reduction in centrally provided ones, will, according to yet further research, depend on their networks and interactions and other levels of social capital. The analysis described in the next section describes an approach for identifying areas that are potentially vulnerable to reductions in service.

\section{Methods}

\section{Overview}

This research describes a method to compare the relationship between different measures of service access - one based on distance and the other based on an attitude survey of service accessibility. By comparing the spatial variation in the relationship between these measures, this analysis aims to identify locales where there are significant differences between how the public perceive their access to services and their geographic distance to that service. It analyses different socio-economic groups to examine whether differences in patterns of group membership and/or distance to services is a predictor of service dissatisfaction. The analysis examines the variation in this relationship for different socio-economic groups described in the OAC classification developed by Vickers and Rees (2007). 
This study analysed the responses to an attitudinal survey in the UK county of Leicestershire, conducted in 2009 by the County Council and associated District Councils as part of the Department of Communities and Local Government's (DCLG) 'Place Survey'. Introduced in 2008, the Place Survey was to be conducted by all local authorities and was designed to both collect data which could be incorporated into the establishment of national indicators relating to local authority delivery against governmentally established normative standards, and also as a way that these authorities, and other local service providers, could gain "direct feedback on services" and explore people's "perceptions of the area" (DCLG 2009, p. 5). In relation to the latter issues, the DCLG allowed the local authorities administering the survey, which was conducted through a postal questionnaire, to include additional questions if they so wished. In the case of the Leicestershire survey, questions were added, asking respondents to describe their satisfaction/dissatisfaction over access to a range of facilities, including Post Offices, libraries, primary health care, childcare, public transport, shops and green spaces. Respondents were asked to indicate their satisfaction/dissatisfaction on a 5-point scale.

The results from each Place Survey have been used in the State of the Countryside Report 2010 (CRC 2010). This report indicates a number of features related to rural vs urban life - bus use, self assessment of health, satisfaction with their area as a place to live, concerns over antisocial behaviour, levels of volunteering, feeling involved in local decision making etc. It was also suggested that there was little rural-urban difference in whether people felt the local authority provided value for money or in assessments as to how well it organised its services. However, it should be noted that this analysis was done at the level of local authority districts, which not only obscure localised spatial variation but may also submerge rural-urban differences given that the "design of territories for local authorities tends to include a mix of urban and rural areas" (RERC 2009, p. 6). For this reason, analysis using smaller scale units, such as the ward or output area, may be much more advantageous.

The Place Survey is a postal survey with a sampling frame selecting household addresses at random from the Post Office small users Address File database. The aim was to reach a sample size of at least 1,100 in each district, regardless of population size. Central government provided the sample of addresses. The questionnaire was sent to households only and was completed by any resident aged 18 or over living at the address. A total of 20,260 questionnaires were sent out and the response rate for each district in Leicestershire was between $41 \%$ and $43 \%$. Leicestershire Statistics and Research Online provide detail of the Place Survey in Leicestershire ${ }^{1}$ and an interactive visualisation of the results. ${ }^{2}$ Leicestershire is a rural county (see Fig. 1), with the City of Leicester (a separate local authority) at the centre. In Leicestershire there were 8530 responses to the survey. For the purposes of this study the data were summarised over Output Areas (OAs) - the finest spatial detail over which census data are reported. There are 1993 OAs in Leicestershire (compared to 133 Wards). Of

\footnotetext{
${ }^{1}$ http://www.lsr-online.org/leicestershire-place-survey-2008.html

2 http://www.lsr-online.org/placesurvey.html
} 


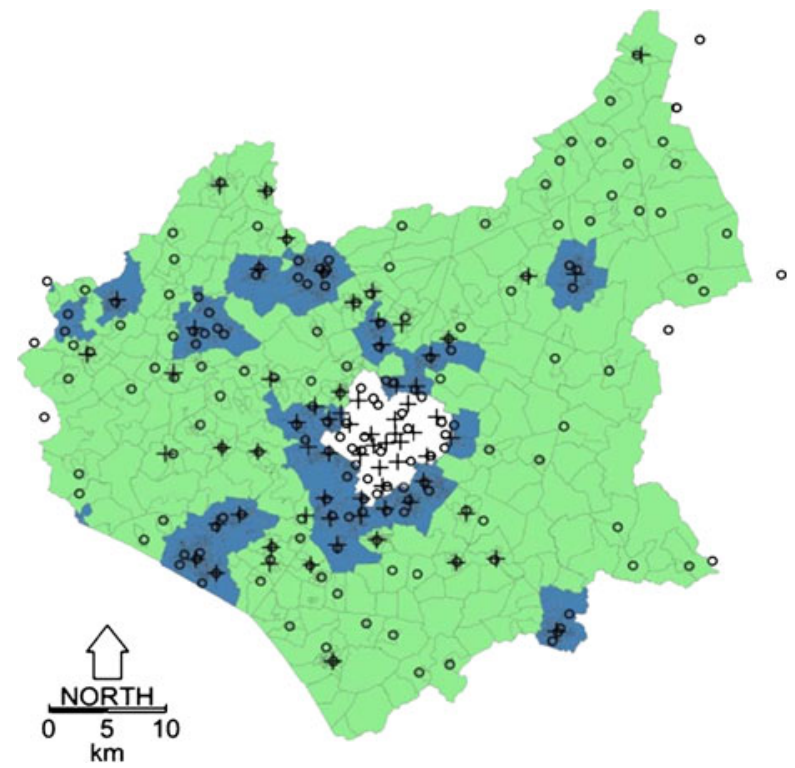

Fig. 1 Rural (light) and urban (dark) OAs in the study area, Leicestershire (UK) with Post office (o) and Library $(+)$ locations indicated

these, 1961 OAs contained Place Survey respondents, providing over $98 \%$ coverage. OAs with no respondents were omitted from the analysis. The number of responses in each OA that expressed dissatisfaction over access to each service were divided by the total number of responses in that OA to generate proportions of respondents who were dissatisfied with their access to Post Offices and libraries.

Summarising the Place Survey data over OAs allowed other OA attributes to be analysed, in this case the OA Classification developed by Vickers and Rees (2007). The OA Classification (OAC) developed by Vickers and Rees (2007) is a geodemographic classification. It was the first freely available geodemographic classification based on data collected for the 2001 Census of England and Wales. It applied a hierarchical k-means classification method (Vickers and Rees 2007), identifying 7 Supergroups at the highest level of classification, 21 Groups at the next level and 52 Subgroups at the lowest level, and descriptive labels were created based on the mean values of the census variables occurring in the seven classes at the highest level. These were Blue Collar Communities, City Living, Countryside, Prospering Suburbs, Constrained-by-Circumstances, Typical Traits, and Multicultural Communities. The OAC clusters were extracted from 41 census variables relating to demographics, household composition, housing, socio-economic (embracing qualifications, car-ownership, travel to work mode, long term illness) and employment. The final set of variables were chosen according to the following criteria: their lack of correlation with other variables or composite variables, their distribution, their consistency across the UK, their certainty, their relevance across the UK and the expected lifetime and longevity of the variable's relevance. A full description of the selection process and the final set of variables are given in Vickers and Rees (2007). 
Analysis

A GIS network analysis determined the road distance from the population-weighted centre of each OA to the nearest facility (Post Office or Library). The Place Survey responses were summarised over each OA as described above. Each OA was allocated to one of 7 OAC classes based on the socio-economic characteristics of the population derived from 2001 Census variable as described in Vickers and Rees (2007).

GWR was used to identify the spatial variation in the relationships between spatial access to services and perceptions of accessibility to that service at the OA level: that is, distance to the nearest facility was locally regressed against the proportion of respondents in each OA who expressed dissatisfaction with access to the facility using GWR. The variation was further analysed by considering the interaction between perceptions of access and geographic access for different OAC groups. GWR analysed the proportion of respondents expressing dissatisfaction over their access to the service in question against geographic distance and OAC class as follows:

$$
y=b_{0\left(u_{i}, v_{i}\right)}+b_{1} x_{1\left(u_{i}, v_{i}\right)}+b_{2} x_{2\left(u_{i}, v_{i}\right)}
$$

where $\mathrm{y}$ is the proportion of respondents dissatisfied over their access, $\mathrm{x}_{1}$ is network distance to the nearest facility and $x_{2}$ describes the OAC groups and the coefficients for each of the predictor variables assumed to vary across the two-dimensional geographical space defined by the coordinates $(u, v)$. The population-weighted centroid of each OA was used as the data point and the GWR results were modelled over a $1 \mathrm{~km}$ grid, with the GWR bandwidth optimised over the function in described Eq. 1. The GWR analysis was done in two stages: first to identify the spatial variation in distance as a predictor of dissatisfaction for all groups, second to analyse the spatial distributions of these relationships for different socio-economic (OAC) groups.

\section{Results}

Initial Analyses

Initial GWR analyses were run to examine the overall relationships between geographic access to Libraries and Post Offices with dissatisfaction over access as expressed through the Place Survey. The aim was to determine whether there was evidence of geographic variation in the relationships, and if so to examine this variation further.

\section{Libraries}

GWR was used to analyse the relationship between the proportion of Place Survey respondents in each OA that were dissatisfied over Library access against geographic distance to the nearest Library. The results are shown in Table 1. It is apparent that, in the case of Libraries, there is little geographic variation in the relationship between geographic distance and perceptions of library accessibility, with the minimum coefficient indicating that dissatisfaction increases universally at around 1.3 percentage points per $\mathrm{km}$. 
Table 1 Summary of the GWR model of the effects of distance to the nearest library as a predictor the proportion of respondents dissatisfied with their access

\begin{tabular}{lcccccc}
\hline & Min & $1^{\text {st }}$ Quartile & Median & $3^{\text {rd }}$ Quartile & Max & Global \\
\hline X Intercept & 1.283 & 1.420 & 1.454 & 1.492 & 1.554 & 1.5068 \\
Library Distance & 1.260 & 1.278 & 1.296 & 1.320 & 1.455 & 1.2694 \\
\hline
\end{tabular}

\section{Post Offices}

In a similar way GWR was used to analyse the spatial variation in the relationship between perceptions of Post Office accessibility against with geographic distance (see Table 2). In this case, there is much more variation than in the case of Libraries, and the global median coefficient of 4.4 percentage points per km actually masks much ' variation in the relationship between levels of dissatisfaction and distance, with dissatisfaction scores over access increasing strongly with increasing geographic distance from a maximum of 24 percentage points per $\mathrm{km}$ in some areas and to a negative relationship in others.

\section{Analysis by Socio-economic Group}

The second part of the analysis sought to identify variations between different OAC groups to see if the relationship between perceptions of service accessibility against geographic distance varies within and between groups. The GWR models were respecified with a different 'Post Office Distance' coefficient for each OAC group. The GWR analyses were then rerun to explore the variation between groups. Two OAC groups were excluded from the analysis due to their low counts in the study area: the Multicultural OAC group which had only 27 OAs and City Living which had 17 OAs. These were omitted from the analysis as to avoid the problem of low geographical variability. For each observation the regression model sets the 'Distance from Post Office' variable to zero for each OAC group except the one that the observation belongs to. For the two OAC groups above, this implied that for large geographical areas, these variables took the value zero, leading to difficulties in calibration.

\section{Libraries}

Little variation between levels of dissatisfaction over library access and geographic distance was found for different OAC groups (Table 3): the global coefficients are

Table 2 Summary of the GWR model of the effects of distance to the nearest Post Offices as a predictor the proportion of respondents dissatisfied with their access

\begin{tabular}{llcccrr}
\hline & Min & $1^{\text {st }}$ Quartile & Median & $3^{\text {rd }}$ Quartile & Max & Global \\
\hline X Intercept & -8.574 & 2.247 & 3.028 & 4.087 & 23.610 & 2.9635 \\
Post Office Distance & -8.952 & 3.455 & 4.391 & 5.106 & 23.940 & 4.1682 \\
\hline
\end{tabular}


Table 3 Summary coefficients describing the relationship between the proportion of people who are dissatisfied with access to Libraries and Distance to Libraries, by OAC group

\begin{tabular}{lccccccc}
\hline OAC Group & Count & Min. & 1stQu. & Median & 3rdQu. & Max. & Global \\
\hline Blue Collar Communities & 233 & 1.316 & 1.324 & 1.343 & 1.376 & 1.391 & 1.353 \\
Countryside & 357 & 1.982 & 1.999 & 2.042 & 2.149 & 2.226 & 2.112 \\
Prospering Suburbs & 836 & 1.334 & 1.383 & 1.394 & 1.413 & 1.441 & 1.432 \\
Constrained by Circumstances & 108 & 2.387 & 2.436 & 2.487 & 2.554 & 2.623 & 2.544 \\
Typical Traits & 382 & 1.088 & 1.129 & 1.141 & 1.15 & 1.159 & 1.162 \\
All OAC groups & 1916 & 1.217 & 1.229 & 1.238 & 1.247 & 1.272 & 1.223 \\
\hline
\end{tabular}

similar for each OAC group with little variation in the minimum, maximum and median coefficient values.

\section{Post Offices}

There was considerable variation in the relationship between levels of dissatisfaction concerning Post Office access and geographic distance to the nearest Post Office (Table 4) than for Libraries. The global and median values indicate the general rate of dissatisfaction with relative remoteness and inter-quartile range (hereafter IQR) gives some indication of the representativeness of that central trend. The global coefficient for All OAC groups shows that dissatisfaction over Post Office access increases with relative remoteness by 4.4 percentage points per $\mathrm{km}$. For some socio-spatial groups the relationships are typically much weaker as indicated by the median coefficient, (e.g. Prospering Suburbs) and for others much stronger (e.g. Constrained by Circumstances). Additionally the within group ranges in the relationship between levels of dissatisfaction over access and geographic distance varies from group to group. For example, the interquartile range of the distribution of the coefficients for Prospering Suburbs is low (less than for All OAC groups), while the highest range is for the OAC group Constrained by Circumstances. The group by group results are described in more detail below and the results considered in relation to the OAC classification summaries available from the

Table 4 Summary coefficients describing the relationship between the proportion of people who are dissatisfied with access to Post Offices and Distance to Post Offices, by OAC group

\begin{tabular}{lccccccc}
\hline OAC Group & Count & Min. & 1stQu. & Median & 3rdQu. & Max. & Global \\
\hline Blue Collar Communities & 233 & -9.26 & 3.416 & 3.799 & 4.577 & 16.51 & 3.380 \\
Countryside & 357 & -18.1 & 1.533 & 2.866 & 3.796 & 27.81 & 2.652 \\
Prospering Suburbs & 836 & -9.90 & 0.897 & 1.399 & 1.841 & 12.02 & 1.875 \\
Constrained by Circumstances & 108 & -6.83 & 5.654 & 6.537 & 8.217 & 19.51 & 6.539 \\
Typical Traits & 382 & -3.98 & 1.786 & 2.461 & 3.286 & 13.63 & 2.193 \\
All OAC groups & 1916 & -4.53 & 3.832 & 4.605 & 5.195 & 20.72 & 4.413 \\
\hline
\end{tabular}




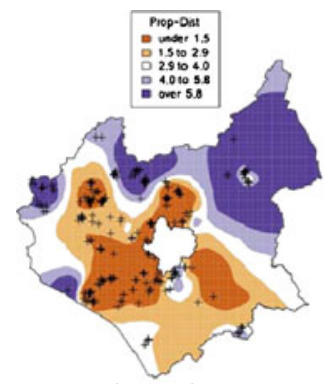

1. Blue Collar Communities

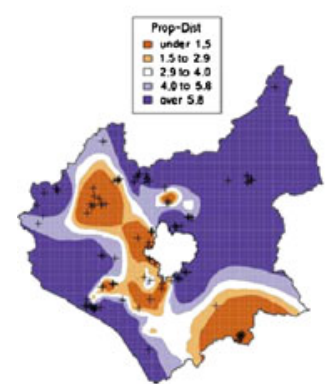

5. Constrained by Circumstances

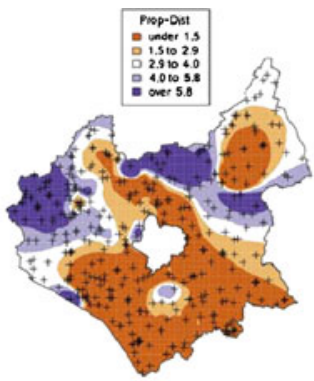

3.Countryside

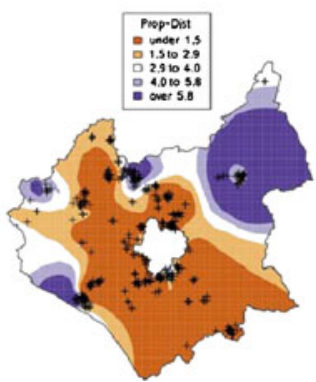

6. Typical Traits

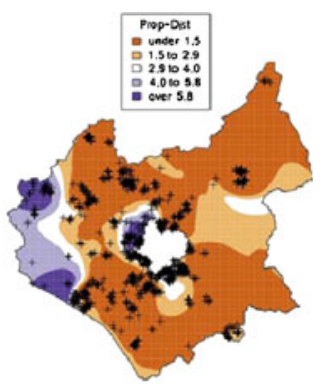

4. Prospering Suburbs

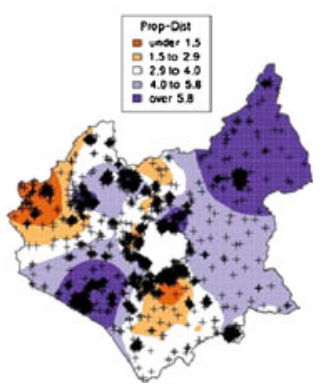

All OAC groups

Fig. 2 Geographical variations in the coefficients of Output Area Dissatisfaction with Post Office access (\%) against Distance to Post Offices $(\mathrm{km})$ for Output Area Classification groups with the centroids of the Output Areas indicated

Office of National Statistics. ${ }^{3}$ Maps of the spatial distribution of the coefficients are shown in Fig. 2 for each OAC group. It should be noted that these maps do not reflect the underlying distribution of OAC groups, rather they show the modelled variation in the relationship between distance and dissatisfaction for those groups.

All OAC Groups When all groups are considered together the greatest increases in dissatisfaction over Post Office with relative remoteness are found North East and South West of the study area. The areas with the lowest increases are to the south and to the North West. However when the spatial distributions of the local coefficients describing this relationship for individual OAC groups are examined, different spatial patterns are evident.

Blue Collar Communities Levels of dissatisfaction over Post Office access increased with relative remoteness for the Blue Collar Communities at around 3.8 percentage points per $\mathrm{km}$ increase in geographic distance. The IQR of coefficients for this group are hence relatively narrow (only Prospering Suburbs has a lower range). This group is associated with a number of characteristics. The Blue Collar Community group has far below average ${ }^{4}$ proportions of the adult population with higher education qualifications and percentage of households which are flats. This group is also associated

\footnotetext{
${ }^{3}$ http://www.statistics.gov.uk/about/methodology_by_theme/area_classification/oa/default.asp

${ }^{4}$ For a variable to be 'far below average' it must have a difference of more than 0.15 below the UK mean
} 
with far above average ${ }^{5}$ percentages of households which are lone parent households with dependent children, of occupied household spaces without central heating, of terraced housing and of households that are public sector rented accommodation. The largest increases in dissatisfaction over Post Office access with distance for Blue Collar Communities occurs in the more rural parts of the study area to the North East and in pockets to the North and to the West. In these areas geographic distance to the nearest Post Office is a strong predictor of dissatisfaction over accessibility.

Countryside Levels of dissatisfaction over Post Office access increases with relative remoteness for the Countryside OAC group at around 2.9 percentage points per $\mathrm{km}$ increase in geographic distance. The IQR of the coefficients for this group is relatively wide (only Constrained by Circumstances has a wider range). The Countryside group is associated with lower than average population density, use of public transport to travel to work and percentage of households which are flats. It has higher than average levels of households with 2 or more cars, people in employment who work mainly from home, detached houses and proportions of the working population who work in agriculture and fishing. The spatial distribution of the coefficients for this group are particularly interesting given the geographic spread of Countryside OAs and the variation in rural areas. High increases in dissatisfaction over Post Office access with relative remoteness are evident in the North West of the study area and in a belt around the North East extremity. The heterogeneity indicated by the IQR and the mapping of the distribution of coefficients may be indicative of different subgroups in this group as indicated in the full OAC classification described by Vickers and Rees (2007): on the one hand the gentrified who have chosen to live in the countryside, travelling to work in their 2 or more cars or working from home and on the other farm workers. It is possible that the gentrified may chose to live in remote areas and so are less dissatisfied over access to Post Offices.

Prospering Suburbs Dissatisfaction over Post Office access increased with relative remoteness for the Prospering Suburbs OAC group at around 1.4 percentage points per $\mathrm{km}$ increase in geographic distance - the lowest of all the OAC groups. The IQR of coefficients for this group is the narrowest indicating a general degree of homogeneity in the relationship between dissatisfaction over Post Office access and relative distance. The Prospering Suburbs OAC group has lower than average levels of public and private sector rented accommodation, terraced housing, flats, and houses without central heating. It is associated with higher than average proportions of detached housing and households with 2 or more cars. The weakness of distance as predictor of dissatisfaction over service access may be expected for this social group who live in the suburbs and who travel regularly for work and for retailing/leisure by car rather than by public transport. As a consequence, such residents may well find it unproblematic to travel to services such as Post Offices, and indeed, may well access these in conjunction with other journeys (e.g. the work commute, the school-run, the shopping trip). The mapping of the distribution of coefficients for this group shows that dissatisfaction over Post Office access increases with relative remoteness in the

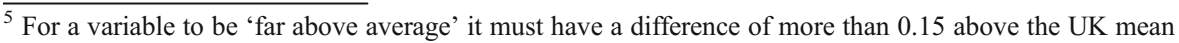


West of the study area: here geographic distance is a strong predictor dissatisfaction about Post Office accessibility.

Constrained by Circumstances Dissatisfaction over Post Office access with relative remoteness increases for the Countryside OAC group at around 6.5 percentage points per km - the highest of all the OAC groups. The range of the coefficients for this group was the widest indicating high within group variation in the degree to which geographic distance is a predictor of dissatisfaction over access. This group is characterised by lower than average levels of detached housing, ownership of 2 or more cars and higher education qualifications, and by higher than average proportions of flats and public sector rented accommodation. The largest increases in dissatisfaction over Post Office access with relative distance are away from the central urban belt and in the more rural parts of the study area to the North East and South West where geographic distance is a strong predictor of dissatisfaction over Post Office access.

Typical Traits The dissatisfaction over Post Office access with relative remoteness for the Typical Traits group increases at around 2.4 percentage points per $\mathrm{km}$ increase in geographic distance. This rate of increase in dissatisfaction and the IQR of coefficients for this group occupy the central values for the 5 groups in each case. This is group is very typical in its characteristics, with only the proportion of public sector rented below average and terraced housing above average. The spatial distribution of coefficients is similar in pattern to the general picture for All OAC groups, with pockets of high increases in the dissatisfaction with distance in the rural areas to North East and some other pockets to the North and West of the study area.

\section{Discussion}

The results show that in this study area distance is a strong predictor of dissatisfaction over access to libraries and Post Offices. They also show that levels of dissatisfaction over Post Office access vary with relative remoteness across the study area whereas for libraries they do not. Little spatial variation in dissatisfaction over geographic access to libraries was found within and between different geodemographic groups, but considerable variation in distance to the nearest Post Office was found within and between particular OAC groups. High coefficients, indicating geographic distance as a stronger predictor of high levels of dissatisfaction, were found for:

- Blue Collar Communities in rural areas;

- Constrained by Circumstances in rural areas, as well as smaller urban areas;

- Countryside in the North and North West;

- Prospering Suburbs in the West;

- Typical Traits in the North East.

Low coefficients indicating geographic distance as a weaker predictor of dissatisfaction were found for:

- Blue Collar Communities in urban areas;

- Constrained by Circumstances in or close to urban areas; 
- Countryside in the extreme North West and around the urban fringe;

- Most of the Prospering Suburbs, except in the West;

- Most of the Typical Traits except in the North East.

These results indicate that geographic distance is good predictor of dissatisfaction for some services but not for others and the variation in the effect of distance within and between socio-economic groups. Whilst some of these results may be selfevident, they may also reflect the trade-offs made at an individual level between the benefits of living in a rural area and the lack of service provision that and service provision can never be uniform at the point of consumption.

The GWR analysis of dissatisfaction over library access found very little spatial variation in the relationship with geographical access and perceptions of accessibility, overall and within and between different OAC groups. In contrast, considerable spatial variation was found for access attitudes and distances in relation to Post Offices. The reasons for may relate to a number of factors. One may be that fewer respondents expressed dissatisfaction over library access (391/8530 respondents) compared to Post Office access (659/8530) suggesting that libraries and access to them may be a less emotive concept than access to Post Offices. People rely on Post Offices for a range of essential services in a way that they do not rely on libraries: they have to use Post Offices whereas they can be seen to choose to use Libraries. Additionally, Post Offices have been the subject of poorly considered recent national and local closure plans (see Comber et al. 2009; Langford and Higgs 2010). The results potentially reflect the different dimensions and processes associated with access to any service for consideration in spatial policy and planning. These relate to the different ways that individuals access different types of service: the perception of access to any given service will be related to geographic and other factors such as cost, previous experience, reputation (first and second hand), perceived quality of service, convenience etc., which will vary depending on the service in question and will be reflected in individual perceptions of access. There may be greater opportunities and choices over some services than others which are reflected in the results of this work: distance was significant factor in respondent perceptions over their access to Post Offices and not to libraries. Variation in the impact of distance over perceptions of access highlights an important point: the concepts of facility 'access' and 'accessibility' involve much more than just geographic or spatial access (Maroko et al. 2009). Much spatial planning assumes that geographic distance is important per se regardless of the nature of the facility, whereas this research has shown that this may not be the case.

Some potential limitations to this study should be noted. First, there is a danger of the results being influenced by the 'ecological fallacy' given the low number of respondents (mean number of respondents per OA 4.3), despite the good spatial coverage of respondents. The implications of this concerns the extent to which the respondents in each $\mathrm{OA}$ adequately characterise that particular census area, and whether their individual social characteristics relate to the OAC characteristics ascribed to them. To quantify any possible impacts a secondary analysis was run for the 396 Lower Super Output Areas in Leicestershire to compare with the OA analysis. LSOAs are composed of around 5 Output Areas (mean number of respondents per LSOA, 21.5). Figure 3 shows that the spatial pattern and distribution of 

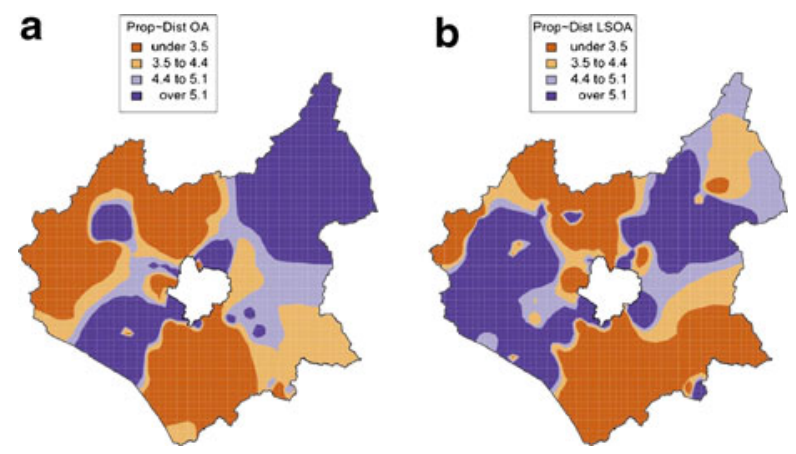

Fig. 3 Comparison of the distribution of the coefficients of the relationship between dissatisfaction over Post Office access as predicted by distance to the nearest Post Office (percentage points per km) when responses are summarised over a Output Areas, b Lower Super Output Areas

distance as a predictor of dissatisfaction for all respondents are similar whether they are analysed by OA or LSOA. Table 5 summarises the distribution of the coefficients associated with distance as predictor of respondent dissatisfaction. The sensitivity of the results is shown in Fig. 3 and Table 5 which indicate that the coefficients and their variation are similar regardless of the census unit used to summarise the data, although the actual distances will be different, due to the differing spatialities. This perhaps suggests that the scale of this relationship is robust at regardless of whether it is analysed at OA or LSOA level and that the GWR analysis allows inferences to be made about how levels of dissatisfaction vary with distance for different social groups depending on the geo-demographic classification of the area they come from. Second, the OAC was selected as the geodemographic classification for analysis in this study because it is freely available and it is commonly used. Whilst census variables could have been selected to describe library and post office users, the use of a predefined geodemographic classification avoids the selection of specific variables related to those services which would require a further level of analysis and would detract from the purpose of this paper: to illustrate the importance of analysing different accessibility dimensions using local statistical methods which identify any variation in the correlations between access distances amongst and between different socio-economic groups for the geodemographic is a proxy. Third, this study developed GWR models of the interaction between dependant and independent variables. GWR makes a number of assumptions. Brunsdon et al. (1998) note that GWR assumes error terms in the model are independent and identically distributed random variables, whereas they are likely to be spatial correlated and Griffith (2008) and Wheeler (2007) develop critical discussions of GWR. However, the aim of this paper was not to develop or extend statistical models but to explore the use of local models to examine

Table 5 A comparison of the GWR coefficients describing the relationship between the proportion of people who are dissatisfied with access to Post Offices with Distance to Post Offices for OAs and LSOAs

\begin{tabular}{llllr}
\hline Census Unit & 1stQu. & Median & 3rdQu. & Global \\
\hline OA & 3.455 & 4.391 & 5.106 & 4.1682 \\
LSOA & 3.298 & 3.902 & 4.607 & 4.0285 \\
\hline
\end{tabular}


the spatial interaction of data originating from different sources and describing different qualities associated with accessibility. Fourth, in this work the relationships between the spatial and some of the experiential dimensions associated with access were explored. It was assumed that any geographical characteristics were explained by consideration of distance to the nearest facility which may not be the case. A range of other factors are also likely to be important. Future work will consider the social and behavioural aspects associated with access as well as social capital including consideration of some of the wider dimensions relating to accessibility that are beyond geographical or spatial factors, such as financial, informational and behavioural influences. This will require a considerable amount of additional data-access behaviours, public transport and car ownership data to construct drive times etc. However, despite these limitations, this work does identify contrasts in the relationships between facilities and how access interacts with geographic distance. The analysis could be further extended in this way through the analysis of geodemographic data on, for example, actual retail spend or the use of public facilities which would allow variation in relationships amongst physical access to services, stated perceptions of access to those services and actual behaviour to be compared and analysed for specific social groups. For example, the inclusion of some measure of the relative reliance on public transport services (Storey and Brannen 2000) would allow issues that have been identified as important for rural women, people with disabilities and for low income groups to be analysed (Little et al. 1991; Halliday 1997; Boardman 1998; Farrington et al. 1998; Halliday and Little 2001; Pavis et al. 2000; Bowden and Moseley 2006). Additionally, the relationships between people's expressed wants and normatively assessed needs may be variable and in some situations may be due to lower accessibility expectations (Farrington and Farrington 2005).

The aim of this work was to quantify and explore some of the different associated with facility access. It compared distance to nearest facility with perceptions of access. This is not to assume that satisfaction over access refers to the nearest facility. Rather it is to test that assumption a) in different places using GWR, b) for different social groups c) for different facilities. The results suggest that in this study area that access dissatisfaction varies across these considerations. The use of GWR to analyse attitude survey data of access dissatisfaction in conjunction with physical measures of access, allowed the relationship between different dimensions of access and accessibility to be examined. One might expect that as distance from services increased so might dissatisfaction over access to that service. Whilst the concept of 'accessibility' is more complex than stated attitudes in postal survey and GIS-based distance measures, this type of analysis can be used to identify the locations where pockets of variation in the attitudes/distance relationship exist for different social groups. For example, areas where dissatisfaction is high and access is high, where dissatisfaction is low and access is low and locations where either dissatisfaction or physical access is low and the other is high. Thus, by considering how such relationships vary in space and across different social groups, this method identifies subgroups that are potentially vulnerable to reductions in service provision. For example, communities where dissatisfaction over service access is high relative to distance may be those with potentially low levels of social capital - although the verification of this suggestion would require further research. 
The current localism/Big Society in the UK initiative reflects a wider phenomenon of reduced spending on public sector services, which has been accompanied by a subtle shift in emphasis in the objective of such work: from seeking to improve coverage, to seeking to determine where services (and thus expenditure) could be reduced. The ability of communities to plug the service gaps resulting from reductions in public service provision is a crucial tenet of the Big Society agenda. Identifying vulnerable communities - those who may not have the social capital to bid for and run facilities at risk of closure or to take over local state-run services as envisioned in the structural reforms being proposed (DCLG 2010) - is important if those groups are not be socially excluded by the changes in service delivery. The use of GWR in this work demonstrates that it is possible to generate a richer analysis of accessibility by considering both the qualitative and quantitative dimensions of access.

\section{Conclusions}

This study suggests the following statements for this study area:

1) Distance is a significant factor in predicting the dissatisfaction over access to both Post Offices (median of 4.4 percentage points per $\mathrm{km}$ ) and libraries (1.3 percentage points per $\mathrm{km}$ ).

2) There is little local variation in the effect of geographic distance as a predictor of library access dissatisfaction.

3) There is considerable spatial variation in the effect of geographic distance over access to Post Offices (up to 23.9 percentage points per $\mathrm{km}$ ).

4) There is considerable spatial variation within and between different socioeconomic (OAC) groups in the effect of geographic distance on Post Office access dissatisfaction indicating that in certain areas the notion of accessibility is related to other factors.

5) There is little variation within and between different socio-economic groups in the effects of geographic distance as a predictor of access dissatisfaction.

Thus, the effects geographic distance as a predictor of access dissatisfaction is stronger for some facilities than others. These effects will spatially vary for some facilities and not for others, indicating that other dimensions of access need to be considered in some cases. Finally, for some facilities the influence of geographic distance on perceptions of access will vary across specific socio-economic groups much more than for others. These findings indicate that studies of access and accessibility should include the multiple dimensions associated with service access such as access behaviours, perceptions, access geographies, etc. In this research considering just 2 of these was found to provide a more rounded analysis of service access. The results also indicate the need for accessibility analyses to include local statistical methods such as GWR to identify the spatial variations in the effect of predictor variables and thereby to provide spatial planning and policy with the ability to spatially target resources and activities. The use of spatially explicitly regression models allows variations in the effect of distance within and between socio-economic to be identified and spatially located. Identifying areas with varying levels of 
dissatisfaction in relation to geographic access identifies where more information about local levels of social capital is needed in order to understand how problems of reduced service provision might be addressed and in turn, to determine areas that may be vulnerable to the impacts of the increased localism agendas such as the Big Society and that may also lack the social capital to organise and run previously state-run facilities and services.

Acknowledgements The authors would like to thank Rob Radburn and Tom Purnell of the Research and Insight Team at Leicestershire County Council, for use of the (anonymised) Place Survey data.

\section{References}

Aday, L. A., \& Andersen, R. (1974). A framework for the study of access to medical care. Health Services Research, 9, 208-20.

Atkin, C. (2003). Rural communities: human and symbolic capital development, fields apart. Compare, 33 (4), 507-518.

Bell, P., \& Cloke, P. (Eds.). (1990). Deregulation and transport: Market forces in the modern world. London: David Fulton.

Bell, P., \& Cloke, P. (1991). Deregulation and rural bus services: a study in rural Wales. Environment and planning $A, 23,107-126$.

Boardman, B. (1998). Rural transport and equity. London: Rural Development Commission.

Bowden, C., \& Moseley, M. J. (2006). The quality and accessibility of services in rural England: A survey of the perspectives of disadvantaged residents. Wolverhampton: Adas UK and University of Gloucestershire.

Bracey, H. E. (1953). Towns as rural service centres: an index of centrality with special reference to somerset. Transactions, Institute of British Geographers, 19, 95-105.

Brunsdon, C. F., Fotheringham, A. S., \& Charlton, M. (1996). Geographically weighted regression-a method for exploring spatial non-stationarity. Geographical Analysis, 28, 281-298.

Brunsdon, C., Fotheringham, A. S., \& Charlton, M. E. (1998). Spatial nonstationarity and autoregressive models. Environment and Planning A, 30, 957-97.

Campaign for Better Transport. (2011a). Save our buses: Defending the country s get up and go ! (London: Campaign for Better Transport) http://bettertransport.org.uk/campaigns/save-our-buses [accessed 7/2/11].

Campaign for Better Transport. (2011b). Buses Matter: a report by Campaign for Better Transport for the RMT. (London: Campaign for Better Transport) http://bettertransport.org.uk/system/files/ Buses+Matter.pdf [accessed 7/2/11].

Comber, A. J., Brunsdon, C., Hardy, J., \& Radburn, R. (2009). Using a GIS-based network analysis and optimisation routines to evaluate service provision: a case study of the UK Post Office Applied Spatial Analysis and Policy, 2(1), 47-64.

Comber, A. J., Sasaki, S., Suzuki, H., \& Brunsdon, C. (2011). A modified grouping genetic algorithm to select ambulance site locations. International Journal of Geographical Information Science, 25(5), $807-823$.

Commission for Rural Communities. (2010). The state of the countryside 2010. Wetherby: Countryside Agency Publications.

Department of Communities and Local Government (DCLG). (2009). Place survey 2008-09: Manual. Wetherby: Communities and Local Government Publications.

Department for Communities and Local Government. (2010). Draft Structural Reform Plan, Department for Communities and Local Government, London www.communities.gov.uk/publications/corporate/ structuralreformplan.

Farrington, J., \& Farrington, C. (2005). Rural accessibility, social inclusion and social justice: towards conceptualisation. Journal of Transport Geography, 13, 1-12.

Farrington, J., Gray, D., Martin, S., \& Roberts, D. (1998). Car dependence in rural Scotland: challenges and policies. Edinburgh: The Scottish Office. 
Findlay, A. M., Stockdale, A., Findlay, A., \& Short, D. (2001). Mobility as a driver of change in rural Britain: an analysis of the links between migration, commuting and travel to shop patterns. International Journal of Population Geography, 7, 1-15.

Forsyth, A., Lytle, L., \& Van Riper, D. (2010). Finding food: Issues and challenges in using Geographic Information Systems to measure food access. Journal of Transport and Land Use, 3(1), 43-65.

Fotheringham, A. S., Charlton, M., \& Brunsdon, C. (1997). Measuring spatial variations in relationships with geographically weighted regression. In M. M. Fischer \& A. Getis (Eds.), Recent developments in spatial analysis, spatial statistics, behavioral modeling and neurocomputing. London: Springer.

Fotheringham, A. S., Charlton, M. E., \& Brunsdon, C. (2001). Spatial variations in school performance: a local analysis using geographically weighted regression. Geographical and Environmental Modelling, $5,43-66$.

Fotheringham, A. S., Brunsdon, C., \& Charlton, M. E. (2002). Geographically weighted regression: The analysis of spatially varying relationships. Chichester: Wiley.

Gray, D., Shaw, J., \& Farrington, J. (2006). Community transport, social capital and social exclusion in rural areas. Area, 38(1), 89-98.

Griffith, D. A. (2008). Spatial-filtering-based contributions to a critique of geographically weighted regression (GWR). Environment and Planning A, 40, 2751-2769.

Halliday, J. (1997). Children s services and care: a rural view. Geoforum, 28, 103-119.

Halliday, J., \& Little, J. (2001). Amongst women: exploring the reality of rural childcare. Sociologia ruralis, 41(4), 423-437.

Higgs, G., \& White, S. D. (1997). Changes in service provision in rural areas. Part 1: the use of GIS in analysing accessibility to services in rural deprivation research. Journal of Rural Studies, 13(4), 441-451.

Huang, Y. F., \& Leung, Y. (2002). Analysing regional industrialization in Jiangsu province using Geographically Weighted Regression. Journal of Geographic system, 4(2), 233-249.

Langford, M., \& Higgs, G. (2010). Accessibility and public service provision: evaluating the impacts of the Post Office Network Change Programme in the UK. Transactions of the Institute of British Geographers, 35(4), 585-601.

Li, T., Corcoran, J., Pullar, D., Robson, A., \& Stimson, R. (2009). A geographically weighted regression method to spatially disaggregate regional employment forecasts for south east Queensland. Applied Spatial Analysis and Policy, 2, 147-175.

Little, J., Ross, K., \& Collins, I. (1991). Women and employment in rural areas. London: Rural Development Commission.

Lowe, P., Bradley, T., \& Wright, S. (1986). Deprivation and welfare in rural areas. Norwich: GeoBooks.

Mahar, C. (1991). On the moral economy of country life. Journal of Rural Studies, 7, 363-372.

Maroko, A. R., Maantay, J. A., Sohler, N. L., Grady, K. L., \& Arno, P. S. (2009). The complexities of measuring access to parks and physical activity sites in New York City: a quantitative and qualitative approach. International Journal of Health Geographics, 8, 34.

McEntee, J., \& Agyeman, J. (2010). Towards the development of a GIS method for identifying rural food deserts: geographic access in Vermont, USA. Applied Geography, 30, 165-176.

Moseley, M. (Ed.). (1978). Social issues in rural Norfolk. Norwich: University of East Anglia.

Moseley, M. (1979). Accessibility: the rural challenge Methuen, London.

Nakaya, T., Fotheringham, A. S., Brunsdon, C., \& Charlton, M. (2005). Geographically weighted poisson regression for disease association mapping. Statistics in Medicine, 24, 2695-2717.

Office, C. (2010). The coalition: Our programme for government. London: Cabinet Office.

Pavis, S., Platt, S., \& Hubbard, G. (2000). Young people in rural Scotland: pathways to social inclusion and exclusion. York: Joseph Rowntree Foundation.

Phillips, M. (2010). Rural community vitality and malaise: moving beyond the rhetoric . In ESRC and Scottish Government (Ed.), Rural community empowerment in the 21 st century: building a can-do culture Economic and Social Research Council, Swindon.

Pinkerton, J., Hassinger, E., \& O’Brien, D. J. (1995). Inshopping by residents of small communities. Rural Sociology, 60, 467-480.

Powe, N. A., \& Hart, T. (2009). Competing for the custom of small town residents: exploring the challenges and potential. International Journal of Retail and Distribution Management, 37(9), 732-747.

Prentice, R. (1991). "Out-shopping" and the externalisation of the Isle of Man retailing economy. Scottish Geographical Magazine, 108, 17-21.

Rural Evidence Research Centre. (2009). Defra classification of Local Authorities in England: updated technical guide (London: Rural Evidence Research Centre) http://www.rerc.ac.uk/ findings/documents_rural/LA_Class_Technical_Guide_April_2009.pdf [accessed 7/2/11]. 
Sasaki, S., Comber, A. J., Suzuki, H., \& Brunsdon, C. (2010). Using genetic algorithms to optimise current and future health planning - the example of ambulance locations. International Journal of Health Geographics, 9, 4. doi:10.1186/1476-072X-9-4.

Sasaki, S., Igarashi, K., Fujino, Y., Comber, A. J., Brunsdon, C., Muleya, C. M., \& Suzuki, H. (2011). The impact of community-based outreach immunization services on immunization coverage with GIS network accessibility analysis in peri-urban areas, Zambia. Journal of Epidemiology and Community Health. doi:10.1136/jech.2009.104190.

Storey, P., \& Brannen, J. (2000). Young people and transport in rural areas. Leicester: Joseph Rowntree Foundation, Youth Work Press.

Tyler, K. (2006). The racialised and classed constitution of English village life. Ethnos, 68(3), 391-412.

Urry, J. (2002). Mobility and proximity. Sociology, 36, 255-74.

Vickers, D. W., \& Rees, P. H. (2007). Creating the national statistics 2001 output area classification. Journal of the Royal Statistical Society, Series A, 170(2), 379-404.

Wheeler, D. (2007). Diagnostic tools and a remedial method for collinearity in geographically weighted regression'. Environment and Planning A, 39, 2464-2481.

White, S. D., Guy, C., \& Higgs, G. (1997). Changes in service provision in rural areas. 2. Changes in post office provision in mid-Wales: a GIS-based evaluation. Journal of Rural Studies, 13(4), 451-465. 